\title{
Ozone therapy in idiopathic carpal tunnel syndrome. Biochemical, neurophysiological and clinical aspects
}

\author{
Marco Willelmo Rascaroli¹, Barbara Borghi ${ }^{1}$, Alessandro Rascaroli2, Valter Travagli3 \\ ${ }^{1} /$ stituti Ospedalieri Bergamaschi by Gruppo San Donato, Italy, ${ }^{2}$ Facoltà di Medicina e Chirurgia, Università degli Studi di Pavia, \\ Italy, ${ }^{3}$ Dipartimento di Biotecnologie, Chimica e Farmacia, Università degli Studi di Siena, Italy
}

\section{○ OPEN ACCESS}

\section{Citation}

Rascaroli MW, Borghi B, Rascaroli A, Travagli V. Ozone therapy in idiopathic carpal tunnel syndrome. Biochemical, neurophysiological and clinical aspects. J Ozone Ther. 2019:2(3) doi: 10.7203/jo3t.2.3.2018.11286

\section{Academic Editor \\ Jose Baeza-Noci, \\ School of Medicine, Valencia University, SPAIN}

\section{Editor}

World Federation of Ozone Therapy, Bologna, ITALY

\section{Received}

December 22, 2017

\section{Accepted}

February 15, 2018

Published

December 15, 2018

\section{Intellectual Property}

Rascaroli MW.

This is an open access article distributed under the terms of the Creative Commons Attribution License (CC BY 4.0), which permits unrestricted use, distribution, and reproduction in any medium, provided the original author and source are credited.

\section{Author Information}

marco.rascaroli@grupposandonato.it

\section{ABSTRACT}

Purpose. Idiopathic Carpal Tunnel Syndrome (CTS) is the most common entrapment neuropathy; however few and only retrospective studies have been found in search engines about Ozone Therapy. The aim of this paper was to evaluate clinical and neurophysiological outcome following Ozone Therapy in CTS. We focused the attention on the evidences concerning the role of Subsynovial Connective Tissue (SSCT) in the pathogenesis of CTS and the ozone pre-conditioning effects linked to pain and inflammatory pathways and to fibrosis induced by Ischemia-Reperfusion Injury.

Materials and methods. Thirty-five patients, aged between 21 and 80 , were stratified clinically by Boston Carpal Tunnel Questionnaire (B.C.T.Q.) and Neurophysiologically by Padua's Gravity Scale classifying patients into five Electro-myographic categories. The mean symptom duration was also recorded. The patients filled in the B.C.T.Q. before and after treatment as well underwent diagnostic neurophysiological tests, strictly standardized in stimulation parameters, electrodes placement and skin temperature. The Ozone Therapy was performed by injecting $4 \mathrm{ml}$ of $\mathrm{O} 2-\mathrm{O} 3$ mixture at $10 \mathrm{ug} /$ $\mathrm{ml}$ concentration under the transverse carpal ligament twice a week for eight sessions.

Results. We compared the B.C.T.Q. scores and the neurophysiological parameters obtained before and after $\mathrm{O} 2-\mathrm{O} 3$ treatment: the improvement of symptoms was significantly greater than the improvement of motor and sensory nerve conduction. The highest clinical improvement degree was found in patients classified in Mild and Moderate Groups.

Discussion and Conclusion. Ischemia-Reperfusion Injury triggers oxidative stress in SSCT with activation of chemical mediators and neo-angiogenesis leading to non-inflammatory fibrosis that represent the allmark of CTS. Previous and retrospective studies based $\mathrm{O} 2-\mathrm{O} 3$ treatment on the main mechanisms of action shared by the treatment of herniated disc in the spine; our study focused the attention on pathophysiology of the SSCT trying to recognize the various stages of CTS pathogenesis by correlating with clinical and neuro-physiological tests. Further studies have to be carried out to better understand these relationships and optimize timing of Ozone Therapy.

Keywords: Ozone therapy, carpal tunnel syndrome, ischemia reperfusion injury, oxidative stress, fibrosis, timing. 


\section{Introduction}

Idiopathic Carpal Tunnel Syndrome (CTS) is the most common entrapment neuropathy; however, inquiring the main search engines, only few and retrospective studies $[37,44]$ are available about Ozone Therapy.

In these papers $\mathrm{O} 2-\mathrm{O} 3$ treatment is based on three main mechanisms of action shared by the treatment of herniated disc in the spine: a) indirect vessel-mediated mechanical decompression of the nerve roots by increasing intra and trans-tissue oxygenation with reduced hypoxia and venous and lymphatic stasis 22; b) action on the cell-mediated inflammatory response both by inhibiting the release of proteinase by macrophages and polymorphonucleates and by increasing immunosuppressive cytokines (interleukin 10, TGF-beta); c) action on the bio-humoral inflammatory response, inhibiting the release of prostaglandins and pro-inflammatory bradykinins

Conversely we have got plenty of papers about pathophysiology of SubSynovial Connective Tissue (SSCT) in CTS.

It is widely accepted that repetitive motion of the wrist, hand and fingers can lead to CTS by a shear strain sufficient to injure the SSCT, triggering a noninflammatory fibrosis of the subsynovial connective tissue, as his histomorphological hallmark.

In the last decade several Authors focused their attention on the different biochemical and vascular pathways that characterize the different stages leading to SSCT fibrosis $[9,11,13,14,15,1617,18,27,39,40,43]$.

We can recognize the early stages by tenosynovial swelling in MRI image [41].

The oxidative stress in subsynovial connective tissue, caused by repeated transient ischemia-reperfusion injury (IRI), was demonstrated by high levels of MDA ( MalonilDiAldehyde, a marker of lipid membrane peroxidation ), upregulation of eNOS (endothelial Nitric Oxide Synthase ) and activation of NF-kb ( a marker of cells immunoreactivity ), with significant positive correlation between subjective symptom severity and immunoreactivities of eNOS and NF-kb [27].

The early stages of CTS are also featured by: a) IL-6 cytokine activation, that leads to inflammatory modulation, stimulation of fibroblastic proliferation and increased sensitivity of nerve endings to pain [36]; b) PGE2 production, that enhances vascular permeability and increases sensitization of nerve endings leading to allodynia, and c) VEGF expression (Vascular Endothelial Growth Factor) that again increases vascular permeability, triggering neoangiogenesis. [9,11,21]

In the intermediate stages of CTS the histological findings in tenosynovium change from edematous to fibrotic.

Various cytokines and growth factors are involved in the development of fibrosis, but TGF- $\beta 1$ is considered to be the most potent and ubiquitous pro fibrogenic cytokine and its signalling and fibrotic gene expression is upregulated in Carpal Tunnel Syndrome [17,18].

Transforming Growth Factor $\beta 1$ and CTGF (Connective Tissue Growth Factor, a cysteine rich peptide) play a synergistic action to promote chronic fibrosis by progressive deposition of Extra Cellular Matrix (ECM) and decrease metalloproteinases activity leading to inhibition of ECM 
degradation and increasing fibrosis [9,39].

It is our knowledge that Ozone Therapy plays a protective role against Ischemia Reperfusion Injury (I.R.I.) [25,26,28,30,31,42] through triggering the antioxidant capacity with increase of SOD and GSH values and reducing the expression of "TLR4-NF-Kb pathway", with decrease of inflammatory molecules and leukocyte recruitment [6].

Several studies showed that Ozone promotes wound healing via induction of Vascular Endothelial Growth Factor (VEGF), Transforming Growth Factor Beta (TGF- $\beta 1$ ) an Platelet-Derived Growth Factor (PDGF), according with the studies of Professor Bocci that demonstrated significantly increase and release of PDGF, TGF- $\beta 1$ and VEGF in presence of Ozone $[3,4,46]$.

We also known that "ozone-induce airway fibrosis" is mediated by increased TGF- $\beta 1$ expression [2].

The aim of the present paper was to design a prospective study to evaluate clinical and neurophysiological outcome following Ozone Therapy in CTS, focusing on the evidences concerning the role of Subsynovial Connective Tissue (SSCT) in the pathogenesis of CTS and trying to temporarily correlate our findings to the effects of ozone on pain and inflammatory pathways and to the different stages characterizing fibrosis induced by IschemiaReperfusion Injury.

\section{Materials and methods}

We designed the first prospective study to evaluate clinical and neurophysiological outcome following Ozone Therapy in CTS, focusing our attention on pathophysiology of SSCT surrounding the flexor tendons in Carpal Tunnel.

We studied thirty-five consecutive patients, 25 women and 10 men, for a total amount of 70 hands, aged between 21 and 80, with History, Clinical and Neurophysiological coherence for idiopathic CTS. All patients underwritten informed consent to treatment.

Patients with other mononeuropathy or polyneuropathy, radiculopathy, systemic comorbidity (such as diabetes, endocrine diseases, inflammatory arthritis or renal failure), previous surgery and concomitant tendinopathies were excluded.

All patients had diagnostic neurophysiological testing, performed using System Plus Evolution by Micromed (Mogliano Veneto, Italy), including electromyography and sensory/motor nerve conduction studies, performed before and after Ozone Therapy, following stringent standardization criteria regarding electrodes placement, stimulation parameters and skin temperature.

Electrodiagnostic findings allowed us to classify the patients into five Groups following the Padua Neurophysiological Classification of CTS [33], as shown in Table 1. 
Table 1. Padua's Classification

\begin{tabular}{|l|l|}
\hline Minimal $(\mathrm{n} 9)$ & $\begin{array}{l}\text { Relative slowdown in comparative sensory test at IV finger vs } \\
\text { ulnar nerve }\end{array}$ \\
\hline Mild $(\mathrm{n} 29)$ & $\begin{array}{l}\text { Sensory slowdown in the palm wrist section with normal value of } \\
\text { motor latency }\end{array}$ \\
\hline Moderate $(\mathrm{n} 20)$ & $\begin{array}{l}\text { Sensory slowdown in the palm wrist section with slight/moderate } \\
\text { increased motor latency }\end{array}$ \\
\hline Severe $(\mathrm{n} 15)$ & $\begin{array}{l}\text { Absence of Sensory Action Potential (SAP) with severe increase } \\
\text { of motor latency }\end{array}$ \\
\hline Extreme $(\mathrm{n} 0)$ & $\begin{array}{l}\text { Absence of Sensory Action Potential (SAP) and Motor Action } \\
\text { Potential ( MAP ) }\end{array}$ \\
\hline
\end{tabular}

Subjective symptom severity was measured using the 11-items Boston Carpal Tunnel Questionnaire (B.C.T.S.) [24,32,34], filled in before and after treatment and the mean symptom duration was also recorded.

The Ozone Therapy was performed by injecting (Fig.1), with a $23 \mathrm{G}$ needle and Antimicrobial filter, $4 \mathrm{~mL}$ of $\mathrm{O} 2-\mathrm{O} 3$ mixture at $10 \mathrm{ug} / \mathrm{mL}$ concentration (produced by Herrmann Medozon Compact in Elsenfeld, Germany) under the transverse carpal ligament, twice a week for eight sessions.

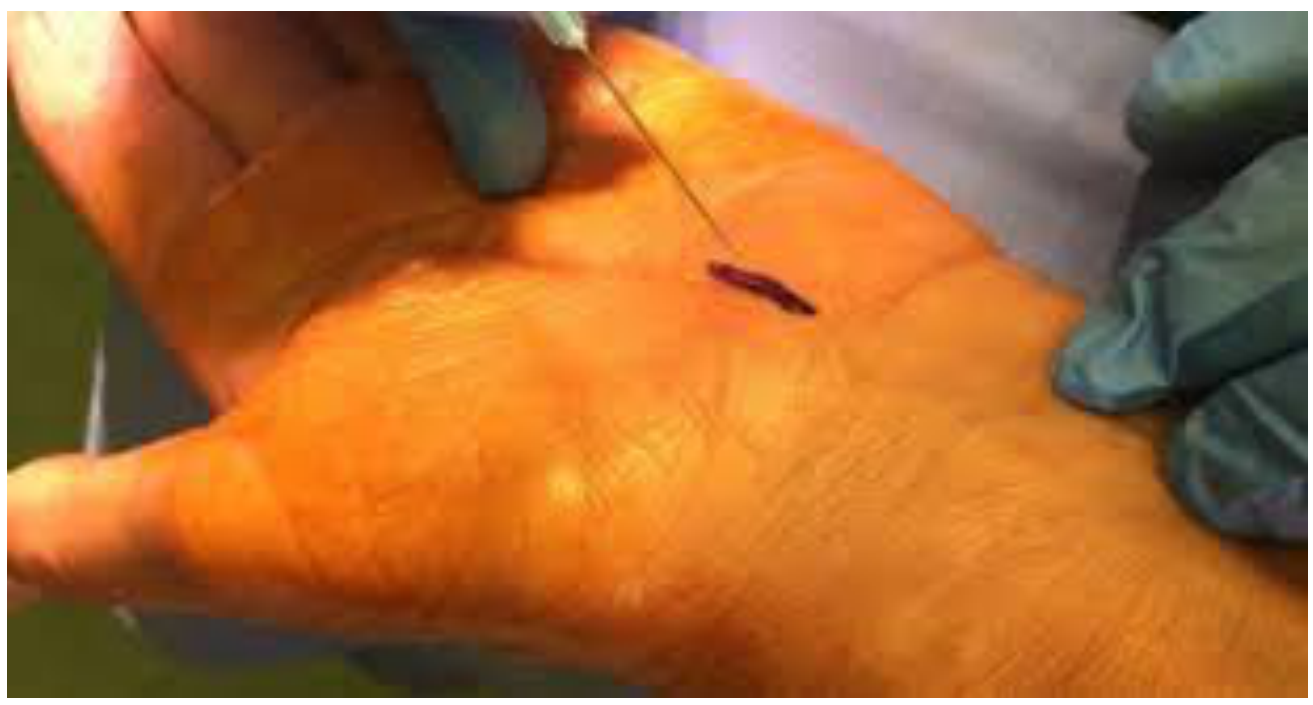

Fig.1. The Ozone Therapy was performed by injecting

\section{Statistical Analysis}

Each patient was assigned to a specific group according to the Padua's classification and for each group a, two-tailed, z-test was performed.

Results are represented in tables 2 and 3 as mean values and mean difference (MD), between values found at diagnosis (Pre) and those after treatment (Post), is applied. Confidence interval of $95 \%$ is shown above and $P$ values of $<0.05$ is considered statistically significant. 


\section{Results}

We compared the B.C.T.Q. scores and the neurophysiological parameters obtained before and after $\mathrm{O} 2-\mathrm{O} 3$ treatment.

Due to the low sample size, we excluded from statistical analysis patients classified into severe Padua's group (table 1); the majority of patients were classified into mild and moderate groups in which we also found the highest clinical improvement degree.

The statistical analysis demonstrated that the improvement of symptoms was significantly greater than the improvement of motor and sensory nerve conduction, according to the previous findings [8,32] about subjective symptoms that not always depend on median nerve functional status or symptom durations and are not always reflected by findings from electrophysiological studies (tables 2 and 3 ).

Table 2 Shows data resulting from the electromyographic evaluation of motor distal latency (MDL) and sensitivity conduction speed (SCS).

\begin{tabular}{|c|c|c|c|c|c|c|c|}
\hline \multicolumn{7}{|c|}{ Minimal } \\
\hline & Pre & Post & MD & SD & Z-test & P-value & $95 \% \mathrm{Cl}$ \\
\hline MDL & 3,500 & 3,456 & 0,044 & 0,093 & 0,956 & 0,171 & $-0,138 / 0,227$ \\
\hline SCS & 46,511 & 47,900 & 1,389 & 1,407 & 1,974 & 0,024 & $-1,369 / 4,147$ \\
\hline \multicolumn{7}{|c|}{ Mild } \\
\hline MDL & 3,683 & 3,575 & 0,108 & 0,056 & 3,892 & $<0,0005$ & $-0,001 / 0,217$ \\
\hline SCS & 41,950 & 44,400 & 2,450 & 1,849 & 2,651 & 0,004 & $-1,173 / 6,073$ \\
\hline & & & Moder & & \\
\hline & Pre & Post & MD & SD & Z-test & P-value & $95 \% \mathrm{Cl}$ \\
\hline MDL & 4,556 & 4,344 & 0,211 & 0,054 & 7,817 & $<0,0005$ & $0,105 / 0,317$ \\
\hline SCS & 37,614 & 39,869 & 2,256 & 1,035 & 4,358 & $<0,0005$ & $0,227 / 4,285$ \\
\hline
\end{tabular}

Table 3 Shows data obtained through the Boston CTS Questionnaire (BCTQ).

\begin{tabular}{|c|c|c|c|c|c|c|}
\hline \multicolumn{7}{|c|}{ Minimal } \\
\hline Pre & Post & MD & SD & Z-test & P-value & $95 \% \mathrm{Cl}$ \\
\hline 15,714 & 6,714 & 9,000 & 1,759 & 10,231 & $<0,0005$ & 5,552 / 12,448 \\
\hline \multicolumn{7}{|c|}{ Mild } \\
\hline Pre & Post & MD & SD & Z-test & P-value & $95 \% \mathrm{Cl}$ \\
\hline 15,600 & 2,800 & 12,800 & 3,323 & 7,705 & $<0,0005$ & $6,288 / 19,132$ \\
\hline \multicolumn{7}{|c|}{ Moderate } \\
\hline Pre & Post & MD & SD & Z-test & P-value & $95 \% \mathrm{Cl}$ \\
\hline 19,056 & 9,000 & 10,056 & 2,057 & 9,775 & $<0,0005$ & $6,023 / 14,088$ \\
\hline
\end{tabular}




\section{Discussion}

Carpal Tunnel Syndrome (CTS) is currently the most frequently encountered peripheral compressive neuropathy.

Clinical and animal models demonstrated the pivotal role of Sub-Synovial Connective Tissue (SSCT) in the pathogenesis of the "idiopathic CTS".

Histo-morphological hallmarks in CTS is a non-inflammatory fibrosis in SSCT, surrounding flexor tendons, leading to the common final pathway for the development of CTS, with increase in interstitial fluid pressure within the carpal canal and the median nerve, owing to microcirculatory venous stasis in a confined space.

Many previous studies showed that ischemia-reperfusion injury (IRI) can be considered the "primum movens" of CTS: in fact the oxidative stress caused by IRI (as well as in many other diseases) triggers a cascade of events characterized by cytokine production in fibroblast and endothelial cells, with vascular hypertrophy and subsequent tissue fibrosis.

Kim, Seol et al. $[19,27]$ emphasized a significant positive correlation between the subjective symptoms severity of CTS and the immunoreactivities of eNOS and NF-K $\beta$. Such evidence suggests that oxidative stress in subsynovial connective tissues contributes to the subjective symptoms, according with previous papers that related clinical aspects to tenosynovial oedematous swelling and MMP-2 activation, especially in the early stages of the disease.

The cascade of events triggered by IRI leads to intermediate stages of CTS in which the histological findings in tenosynovium change from edematous to fibrotic.

Several Authors have identified the increased expression of fibrotic factors such as transforming growth factor - beta (TGF- $\beta 1$ ), connective tissue growth factor, (CTGF), type 1 collagen (Col1) and type 3 collagen (Col3) in the SSCT from CTS patients.

Latest studies explored the nature of the fibrotic expression found in the SSCT of patients with CTS and noted significantly increased gene expression for Col1 and 3 , TGF- $\beta$ and SMAD3 in CTS fibroblasts. These studies also examined blocking TGF- $\beta$ signaling in CTS and suggest that therapies targeted for the TGF- $\beta$ signaling pathway may ultimately have utility for the prevention and/or treatment of CTS as well as the anti-fibrotic effect of relaxin [22,23].

In the intermediated stages of CTS, many studies showed neovascularization and vascular pathologic changes mediated by VEGF activation: hypoxia downregulates tropoelastin gene expression with consequent decreased elastogenesis, triggering a vicious cycle of tenosynovial ischemia-reperfusion.

We designed our study considering all the pathophysiological evidence in SSCT described above and reviewing the knowledge about ozone, especially regarding its interaction with pain mediators, its protective role against Ischemia Reperfusion Injury and its role in wound healing, as reported extensively in reference chapter.

As neurophysiological knowledge teaches us, sensory conduction velocity and motor latency provide information about myelin sheet which is first involved by pressure increasing in carpal tunnel confined space; the amplitude of Motor and Sensory Action Potentials ( CMAP and CSAP) is instead related to the number of axon, therefore its reduction means loss of axons. 
The majority of our patients was neurophysiologically classified in Mild and Moderate Padua's groups: as shown in Table 2, in these groups we found a slight statistical improvement in motor and sensory parameters, according with low Confidence Interval.

Evaluating the B.C.T.Q. score in Mild and Moderate groups (Table 3) the clinical improvement results highly statistical significant as shown by high Confidence Interval.

Minimal, mild and moderate Padua's groups could represent the pathophysiological "early stages", in which tenosynovial swelling leads to increasing pressure in carpal tunnel resulting in only slow speeds without reduction in amplitude that means no axonal loss.

The high improvement in clinical symptoms after Ozone therapy in mild and moderate groups could be explained by its documented protective effects against Ischemia-Reperfusion Injury and consequent oxidative stress cascade.

When histological findings in tenosynovium change from oedematous to fibrotic we could recognize the transition from early to intermediate stage, characterized by progressive thickening of the SSCT resulting in a steady increase in pressure that leads to progressive axonal degeneration.

Regarding the references about biological and therapeutic effects of Ozone there are many evidences in wound healing via induction of Vascular Endothelial Growth Factor (VEGF), Transforming Growth Factor Beta (TGF$\beta 1)$ and Platelet-Derived Growth Factor (PDGF), as previous demonstrated by studies of Professor Bocci [3,4].

This profibrotic action of ozone leads us to a critical evaluation of the use of ozone in intermediate stages of CTS, in which Transforming Growth Factor Beta (TGF- $\beta 1$ )is Upregulated, opening, conversely, doors for targeted drug therapies by blocking fibrotic signaling in fibroblasts in patients with CTS [22].

The present paper demonstrates that we need further prospective studies to define the optimal timing of Ozone Therapy, not only about CTS, regarding its biological complexity of action and its relationship with different stages in various diseases $[38,45]$.

\section{References}

1. Alfonso C, Jann S, Massa R, Torreggiani A. Diagnosis, treatment and follow-up of the carpal tunnel syndrome: a review. Neurolog Sci. 2010;31(3):243-252. doi: 10.1007/s10072-009-0213-9.

2. Katre A, Ballinger $\mathrm{C}$, Akhter $\mathrm{H}$, Fanucchi M, Kim DK, Postlethwait E, et al. Increased transforming growth factor beta 1 expression mediates ozoneinduced airway fibrosis in mice. Inhal Toxicol. 2011;23(8):486-494. doi: 10.3109/08958378.2011.584919.

3. Bocci V, Luzzi E, Corradeschi F, Silvestri S. Studies on the biological effects of ozone. Production of transforming growth factor 1 by human blood after ozone treatment. J Biol Regul Homeost Agents. 1994;8(4): 108-112.

4. Valacci G, Bocci V. Studies on the biological effects of ozone. Release of factors from ozonated human platelets. Mediators Inflamm. 1999;8(4-5): 205-209.

5. Bonetti M. Oxygen-Ozone Therapy: Brief historical review and mechanism of action. Int J Ozone Ther. 2007;6(2):143-144. 
6. Xing B, Chen H, Wang L, Weng X, Chen Z, Li X. Ozone oxidative preconditioning protects the rat kidney from reperfusion injury via modulation of the TLR4-NF-KB pathway. Acta Cir Bras. 2015;30(1):60-6. doi: 10.1590/S0102-86502015001000008.

7. Chammas M, Boretto J, Burmann LM, Ramos RM, Dos-Santos-Neto FC, et al. Carpal tunnel syndrome - Part I (anatomy, physiology, etiology and diagnosis). Rev Bras Ortop. 2014;49(5):429-36. doi: 10.1016/j.rboe. 2014.08.001.

8. Chan L, Turner JA, Comstock BA, Levenson LM, Hollingworth W, Heagerty PJ, et al. The relationship between electrodiagnostic findings and patient symptoms and function in carpal tunnel syndrome. Arch Phys Med Rehabil. 2007;88(1):19-24.

9. Chikenji T, Gingery A, Zhao C, Passe SM, Ozasa Y, Larson D, et al. Trasforming growth factor- $\beta$ (TGF- $\beta$ ) expression is increased in the subsynovial connective tissues of patients with idiopathic carpal tunnel syndrome. J Orthop Res. 2014;32(1):116-122. doi: 10.1002/jor.22485.

10. Ciliberti S, Marchese D, D'Andrea M, Meliado R, Fratto L, Amendola GAM, et al. Sindrome del tunnel carpale: Review [Carpal tunnel syndrome: review] [Internet]. Consenza: Editore Claudio Constanzo; 2015[cited 2019 Mar 15]. Available from: https://portale.ilcentrotirreno.it/ pubblicazioni-scientifiche/745-sindrome-del-tunnel-carpale-review.html

11. Deger AN, Deger H, Taser F. The role of neoangiogenesis and vascular endothelial growth factor in the development of carpal tunnel syndrome in patients with diabets. Niger J Clin Pract. 2016;19(2):189-95. doi: 10.4103/1119-3077.175971.

12. Di-Silvestri CA, Cosentino P, Buscema A, Pizzolo S, Condorelli G. Diagnosi e trattamento della sindrome del tunnel carpale [Diagnoses and treatment of carpal tunnel syndrome] [Internet]. [place unknown]: Fisiobrain; 2013[cited 2019 Mar 15]. Available from: http:// www.fisiobrain.com/web/2013/diagnosie-trattamento-della-sindrome-deltunnel-carpale

13. Ettema AM, Amadio PC, Zhao C, Wold LE, An KN. A histological and immunohistochemical study of the subsynovial connective tissue in idiopathic carpal tunnel syndrome. J Bone Joint Surg Am. 2004;86A(7): 1458-1466.

14. Tucci MA, Barbieri RA, Freeland AE. Biochemical and histological analysis of the flexor tenosynovium in patients with carpal tunnel syndrome. Biomed Sci Instrum. 1997;33:246-251.

15. Sud V, Freeland AE. Biochemistry of carpal tunnel syndrome. Microsurgery. 2005;25(1):44-46. doi: 10.1002/micr.20071.

16. Freeland AE, Tucci MA, Barbieri RA, Angel MF, Nick TG. Biochemical evaluation of serum and flexor tenosynovium in carpal tunnel syndrome. Microsurgery. 2002;22(8):378-85.

17. Gingery A, Yang TH, Passe SM, An KN, Zhao C, Amadio PC. TGF- $\beta$ signaling regulates fibrotic expression and activity in carpal tunnel syndrome. J Orthop Res. 2014;32(11):1444-1450. doi: 10.1002/jor. 22694.

18. Chikenji T, Gingery A, Zhao C, Passe SM, Ozasa Y, Larson D, et al. Transforming growth factor- $\beta$ (TGF- $\beta$ ) expression is increased in the subsynovial connective tissues of patients with idiopathic carpal tunnel syndrome. J Orthop Res. 2014;32(1):116-122. doi: 10.1002/jor.22485. 
19. Seol GH, Kang P, Lee HS, Seol GH. Antioxidant activity of linalool in patients with carpal tunnel syndrome. BMC Neurol. 2016;16:17. doi: 10.1186/s12883-016-0541-3.

20. Hirata H, Tsujii M, Yoshida T, Imanaka-Yoshida K, Morita A, Okuyama N, et al. MMP-2 expression is associated with rapidly proliferative arteriosclerosis in the flexor tenosynovium and pain severity in carpal tunnel syndrome. J Pathol. 2005;205:443-450.

21. Jinrok O, Zhao C, Amadio PC, An KN, Zobitz ME, Wold LE. Vascular pathologic changes in the flexor tenosynovium (subsynovial connective tissue) in idiopathic carpal tunnel syndrome. J Orthop Res. 2004;22(6): 1310-1315. doi: 10.1016/j.orthres.2004.03.005.

22. Yamanaka Y, Gingery A, Oki G, Yang TH, Zhao C, Amadio PC. Blocking fibrotic signaling in fibroblasts from patients with carpal tunnel syndrome. J Cell Physiol. 2018;233(3):2067-2074. doi: 10.1002/jcp.25901.

23. Kang YM, Lee HM, Moon SH, Kang H, Choi YR. Relaxin modulates the expression of MMPs and TIMPs in fibroblasts of patients with carpal tunnel syndrome. Yonsei Med J. 2017;58(2):415-422. doi: 10.3349/ymj. 2017.58.2.415.

24. Levine DW, Simmons BP, Koris MJ, Daltroy LH, Hohl GG, Fossel AH, et al. A self-administered questionnaire for the assessment of severity of symptoms and functional status in carpal tunnel syndrome. J Bone Joint Surg Am. 1993;75(11):1585-1592.

25. Wang L, Chen H, Liu XH, Chen ZY, Weng XD, Qiu T, et al. Ozone oxidative preconditioning inhibits renal fibrosis induced by ischemia and reperfusion injury in rats. Exp Ther Med. 2014;8(6):1764-1768. doi: 10.3892/etm.2014.2004.

26. Kal A, Kal O, Akillioglu I, Celik E, Yilmaz M, Gonul S, et al. The protective effect of prophylactic ozone administration against retinal ischemiareperfusion injury. Cutan Ocul Toxicol. 2017;36(1):39-47. doi: 10.3109/15569527.2016.1156120.

27. Kim JK, Koh YD, Kim JS, Hann HJ, Kim MJ. Oxidative stress in subsynovial connective tissue of idiopathic carpal tunnel syndrome. J Orthop Res. 2010;28(11):1462-1468. doi: 10.1002/jor.21163.

28. Meng W, Xu Y, Li D, Zhu E, Deng L, Liu Z, et al. Ozone protects rat heart against ischemia-reperfusion injury: a role for oxidative preconditioning in attenuation mitochondrial injury. Biomed Pharmacother. 2017;88:1090-1097. doi: 10.1016/j.biopha.2017.01.151.

29. Baeza-Noci J, Cabo-Soler JR, Moraleda-Gomez M, Menendez-Cepedo S, Re L. WFOT's Review on Evidence Based Ozone Therapy [Internet]. Brescia: WFOT; 2015[cited 2019 Mar 15]. Available from: https:// www.wfoot.org/wp-content/uploads/2016/01/WFOT-OZONE-2015ENG.pdf.

30. Onal M, Elsurer C, Selimoglu N, Yilmaz M, Erdogan E, Bengi-Celik J, et al. Ozone prevents cochlear damage from ischemia-reperfusion injury in Guinea pigs. Artif Organs. 2017;41(8):744-752. doi: 10.1111/aor.12863.

31. Onal O, Yetisir F, Sarer AE, Zeybek ND, Onal CO, Yurekli B, et al. Prophylactic ozone administration reduces intestinal mucosa injury induced by intestinal ischemia-reperfusion in the rat. Mediators Inflamm. 2015;2015:792016. doi: 10.1155/2015/792016.

32. Padua L, Padua R, Aprile I, Amico P, Tonali P. Carpal tunnel syndrome: relationship between clinical and patient-oriented assessment. Clin Orthop Relat Res. 2002;395:128. 
33. Padua L, Lo-Monaco M, Padua R, Gregori B, Tonali P. Neurophysiological classification of carpal tunnel syndrome: assessment of 600 symptomatic hands. Ital J Neurol Sci. 1997;18(3):145-150.

34. Padua R, Padua L, Romanini E, Aulisa L, Lupparelli S, Sanguinetti C. Versione italiana del questionario "Boston Carpal Tunnel": valutazione preliminare [Italian version of "Boston Carpal Tunnel" questionaire: preliminary valutation]. G Ital Ortop Traum. 1998;24(1):121-129.

35. Ramonda R, Punzi L, Vangelista T, Todesco S. Analisi critica delle manovre semeiologiche proposte per la diagnosi di sindrome del tunnel carpale [Critical analysis of the manoeuvres proposed for the diagnosis of the tunnel carpal syndrome]. Reumatismo. 2002;54(2):156-164.

36. Re L, Sanchez G. M, Mawsouf N. Clinical evidence of ozone interaction with pain mediators. Saudi Med J. 2011;32(12):1363-1367.

37. Scarchilli A. Sindrome del tunnel carpale (STC) [Carpal tunnel Syndrome (CTS)]. Int J Ozone Ther. 2009;8(2):150-152.

38. Somay H, Emon ST, Uslu S, Orakdogen M, Meric ZC, Ince U, et al. The histological effects of ozone therapy on sciatic nerve crush injury in rats. World Neurosurg. 2017;105:702-708. doi: 10.1016/j.wneu.2017.05.161.

39. Chikenji T, Gingery A, Zhao C, Vanhees M, Moriya T, Reisdorf R, et al. Transforming growth factor- $\beta$ (TGF- $\beta$ ) expression is increased in the subsynovial connective tissue in a rabbit model of carpal tunnel syndrome. PLoS One. 2014;9(9):108312. doi: 10.1371/journal.pone. 0108312.

40. Tat J, Wilson KE, Keir PJ. Pathological changes in the subsynovial connective tissue increase with self-reported carpal tunnel syndrome symptoms. Clin Biomech (Bristol, Avon). 2015;30(4):360-365. doi: 10.1016/j.clinbiomech.2015.02.015.

41. Tsujii M, Hirata $H$, Morita A, Uchida A. Palmar bowing of the flexor retinaculum on wrist MRI correlates with subjective reports of pain in carpal tunnel syndrome. J Magn Reson Imaging. 2009;29(5):1102-5. doi: 10.1002/jmri.21459.

42. Tusat M, Mentese A, Demir S, Alver A, Imamoglu M. Medical Ozone therapy reduces oxidative stress and testicular damage in an experimental model of testicular torsion in rats. Int Braz $\mathrm{J}$ Urol. 2017;43(6):1160-1166. doi: 10.1590/S1677-5538.IBJU.2016.0546.

43. Werthel JD, Zhao C, An KN, Amadio PC. Carpal tunnel syndrome pathophysiology: role of subsynovial connective tissue. J Wrist Surg. 2014;3(4):220-6. doi: 10.1055/s-0034-1394133.

44. Zambello A, Fumagalli L, Fara B, Bianchi MM. Oxigen-ozone treatment of carpal tunnel syndrome. Retrospective study and literature review of conservative and surgical techiques. Int J Ozone Ther. 2008;7(1):45-48.

45. Zanardi I, Borrelli E, Valacchi G, Travagli V, Bocci V. Ozone: Multifaceted Molecule with Unexpected Therapeutic Activity. Curr Med Chem. 2016;23(4):304-14.

46. Zhang J, Guan M, Xie C, Luo X, Zhang Q, Xue Y. Increased growth factors play a role in wound healing promoted by noninvasive oxygenozone therapy in diabetic patients with foot ulcers. Oxid Med Cell Longev. 2014;2014:273475. doi: 10.1155/2014/273475. 